indifferent incisions, and in two cases where the iris rose above the knife, the complete iridectomies followed the normal course during convalescence.

In assessing the relative merits of the two methods of extraction one must consider two factors: (a) the von Graefe method is simple and quick, and has withstood the test of time and usage in many thousands of cases: its drawbacks are known and its complications understood; (b) the keratome and scissors method, though theoretically preferable, is complicated and takes longer; yet it results in a completely sutured eye which follows normal surgical procedure.

With regard to the instruments introduced into the eye, more than two must be used whichever method is employed; the number of instruments should not cause either method to be condemned, and the sharpness of knife or keratome can be no criterion, for before the eye is entered one feels whether the point is satisfactory or not, and it is simple to take another from the instrument rack.

The experienced surgeon will be slow to drop a method which has given excellent results in his hands: the tyro will adopt the method on which he is brought up: the indifferent surgeon will remain indifferent whatever technique he attempts.

The whole subject, with an emphasis on those cases which go wrong, would form an excellent topic for a major item at one of our Congresses; it is of sufficient importance to warrant a thorough discussion " at the highest level ".

Yours faithfully,

Frank R. Neubert.

Hauterive, The Queen's Road,

GUERNSEY. July 10, 1951.

\title{
SIGHT OF UNDERGRADUATES
}

\section{To the Editorial Committee of the}

\section{BRITISH JourNal OF OPHTHALMOLOGY}

DEAR SIRS-The author of the paper entitled Sight of Undergraduates (British Journal of Ophthalmology, 35, 467) includes in his summary a statement that " the sight of undergraduates is four times worse than that of 18-year-old men in the general population ", but no such conclusion can be drawn from the facts presented. The author's Table IV certainly shows that his sample of undergraduates contained rather more than four times as many poor-sighted persons as would be expected among a 
corrèsponding number of persons of similar age drawn from the general community, but this finding is not equivalent to the one formulated in his summary.

On the basis of acuity, it would be true to say that the sight of the undergraduates is four times worse than that of the general community of 18-year-old males, only if, for example, on the average, the undergraduates had $\mathrm{V}=6 / 24$, while, on the average, the non-undergraduates had $\mathrm{V}=6 / 6$. No such relation of acuities is exhibited in the author's data. On the contrary, the 'average vision' for "other young men" is " $6 / 6$ or better in one eye, the other worse ", while the average vision for the undergraduates is "6/9-6/12 in one eye, the other worse". So, on the evidence adduced, it may be said, at worst, that the sight of undergraduates is about half as good as that of 18-year-old men in the general population.

Though slight, the evidence in the paper that visual acuity declines even between 17 and 25 years of age is interesting; the present writer has published data (British Journal of Ophthalmology, 32, 645) showing that visual performance declines from early adulthood.

\section{Yours faithfully,}

Group for Research in Occupational Optics,

H. C. WESTON

INSTITUTE OF OPHTHALMOLOGY, JudD STREET, W.C.1.

August 14, 1951.

To the Editorial Committee of the

\section{BRITISH JOURNAL OF OPHTHALMOLOGY}

DEAR SiRs-Mr. Weston agrees with me that the sight of undergraduates is substantially worse than that of young men in the general population, but I am grateful to him for eliminating some ambiguity in my summary. As he suspects, it was, of course, intended to convey that four times as many undergraduates had poor sight. Mr. Weston introduces the concept of average visual acuity. I had omitted this because the distribution of visual acuity seemed more instructive than the mean.

May I also have your permission to correct an error? The young male recruits referred to by Dr. W. J. Martin (M.R.C. Memo. No. 20, p. 3) were between the ages of 20 and 21 , not 18 years old as stated in my paper. Recognition of this, if anything, strengthens the conclusions drawn from comparison of undergraduates with the general population.

Yours faithfully,

Institute of Social Medicine,

R. W. PARnell

10, Parks Road, Oxford.

September 7, 1951. 